\title{
Early Stage Pulmonary Embolism Because of Stab Wound Injury Without Vascular Penetration
}

\author{
Semih Petekkaya', Nusret Ayaz², Mustafa Doğan³, Mücahit Oruç4, Erdem Okdemir, Osman Celbis² \\ 'Department of Forensic Medicine, Abant İzzet Baysal University School of Medicine, Bolu, Turkey \\ 2Department of Forensic Medicine, Inönü University School of Medicine, Malatya, Turkey \\ 3Justice Ministry, Council of Forensic Medicine, Iğdır Branch, Iğdır, Turkey \\ ${ }^{4}$ Justice Ministry, Council of Forensic Medicine, Malatya Group Chairmanship, Malatya, Turkey
}

Cite this article as: Petekkay S, Ayaz N, Doğan M, Oruç M, Okdemir E, Celbis O. Early Stage Pulmonary Embolism Because of Stab Wound Injury Without Vascular Penetration. J Emerg Med Case Rep 2017; 8: 76-9.

\begin{abstract}
Introduction: Pulmonary embolism, occurring as a result of acute obstruction of the pulmonary artery system, may vary from the frequently observed asymptomatic clinical state to sudden death and is a disease with high morbidity and mortality rates. Pulmonary embolism is most commonly observed within 5-7 days of trauma and has been occasionally reported before 4 days.

Case Report: A 40-years-old female was admitted to emergency service with a knife wound injury. Her vital and laboratory values were normal. Physical examination revealed a knife wound injury, measuring $2 \times 1 \mathrm{~cm}$, on the femoral midline of the left leg. Then, she was discharged. After approximately $6 \mathrm{~h}$, she presented to another emergency service with complaints of chest pain and syncope. During evaluation, she developed cardiopulmonary arrest and died because of pulmonary embolism.

Conclusion: This report presents a case of early stage pulmonary embolism that developed because of circulation disruption caused by the effect of pressure as a result of a localized hematoma owing to an indirect effect of a stab wound injury with no vascular penetration injury.
\end{abstract}

Keywords: Pulmonary embolism, stab wound injury, forensic case

Received: 25.09.2016 Accepted: 13.01.2017 Available Online Date: 05.05.2017

\section{Introduction}

Pulmonary embolism that occurs as a result of acute obstruction of the pulmonary artery system may vary from the frequently observed asymptomatic clinical state to sudden death and has high morbidity and mortality rates $(1,2)$. In the United States of America, pulmonary embolism is the most commonly observed cardiovascular system disease, after acute ischemic syndrome and stroke (3). The first (4). In approximately $25 \%$ of patients, the initial manifestation of PE could be sudden-unexpected death (4). In $>50 \%$ of cases of fatal pulmonary embolism, diagnosis is made during autopsy (5). The formation of a thrombus was first described by Rudolph Virchow in 1884 as hypercoagulability, stasis, and vascular wall damage; this information remains current $(3,4)$. Strong factors underlying thromboembolism are fractures and spinal cord damage; moderate factors are central venous catheter, malignancy, oral contraceptive therapy, paralytic stroke, history of venous thromboemboli, and thrombophilia; and weak factors are $>3$ days of bedrest, lack of movements because of lengthy periods of sitting, and varicose veins (6). Studies have reported that acute thrombosis develops with advanced age, obesity, penetrating wound, blunt trauma-related injuries, hip or knee joint replacement, major surgical interventions, and major trauma $(5,6)$.

This report presents a case of early stage pulmonary embolism that developed because of circulation disruption caused by the effect of pressure as a result of a localized hematoma owing to a stab wound injury with no vascular penetration injury.

It has been presented as poster at XII. Forensic Sciences Congress, 4-6 June 2015 Isparta, Turkey.

Address for Correspondence:

Nusret Ayaz, Department of Forensic Medicine, Inönü University School of Medicine, Malatya, Turkey

E-mail: nusretayaz@gmail.com

oCopyright 2017 by Emergency Physicians Association of Turkey - Available online at www.jemcr.org 


\section{Case Report}

A 40-years-old female presented to the emergency department with a knife wound injury. The general status of the patient was good, and she was conscious. Physical examination revealed a knife wound injury, measuring $2 \times 1 \mathrm{~cm}$, on the femoral midline of the left leg and an hematoma, measuring $5 \times 10 \mathrm{~cm}$. Laboratory examinations revealed that the hemogram values were within normal limits.

Doppler ultrasound of the left extremity revealed a lesion with a heterogeneous hypoechoic appearance, measuring $5.5 \times 3.5 \times 10 \mathrm{~cm}$ at the widest point, on the muscle planes of the medial section of the left thigh. The level of the lesion was observed to have resulted in the deep and superficial femoral artery branches being under pressure. In the examination and tests performed by a cardiac vascular specialist, a $2 \mathrm{~cm}$ stab wound injury was observed in the posterior of the left thigh, with no heat or loss of movement in the left lower extremity; no vascular injury was observed on Doppler ultrasound. Triphasic blood flow was observed in the popliteal artery and tibialis posterior, and because no emergency vascular pathology was observed, the patient was discharged.

Approximately $6 \mathrm{~h}$ after the first presentation, the patient presented again at the emergency department of another hospital with complaints of chest pain and syncope. Brain computed tomography (CT) findings were normal. According to the cardiac enzyme and electrocardiography (ECG) findings, no pathology was considered by the cardiology department, and follow-up was recommended. However, when the patient visited the washroom, she again experienced syncope. Diffusion brain magnetic resonance imaging revealed an appearance that was consistent with an acute infarct, showing restricted diffusion in the posteromedial left temporal lobe and left thalamus, echocardiograph revealed right ventricle dilatation findings, and thorax CT and dynamic thorax CT revealed hypodense thrombus material in both the inferior pulmonary artery branches (Figure 1).

At approximately $12 \mathrm{~h}$ from the onset of symptoms, the patient died because of cardiopulmonary arrest associated with pulmonary embolism. In the medical history of the patient, no record was found of any medical disease or use of medication, which could have caused the pulmonary embolism.

Although this was a forensic case, a burial certificate was prepared with the diagnosis of pulmonary embolism without notifying the forensic authorities. As the family of the deceased lodged a complaint and the husband claimed that the cause of death was the knife injury, exhumation procedures were performed 39 days after the date of death, and an autopsy was conducted.

In the autopsy, external examination revealed widespread larva activity over the whole body, epidermal stripping, and yellow-blackred-brown color changes on the whole body; the eyeballs had lost formation because of decay, three pieces of blue suture material were observed on the mid-third of the posterior surface of the left thigh, and the stab wound injury was seen at a depth of $2.5 \mathrm{~cm}$, in-

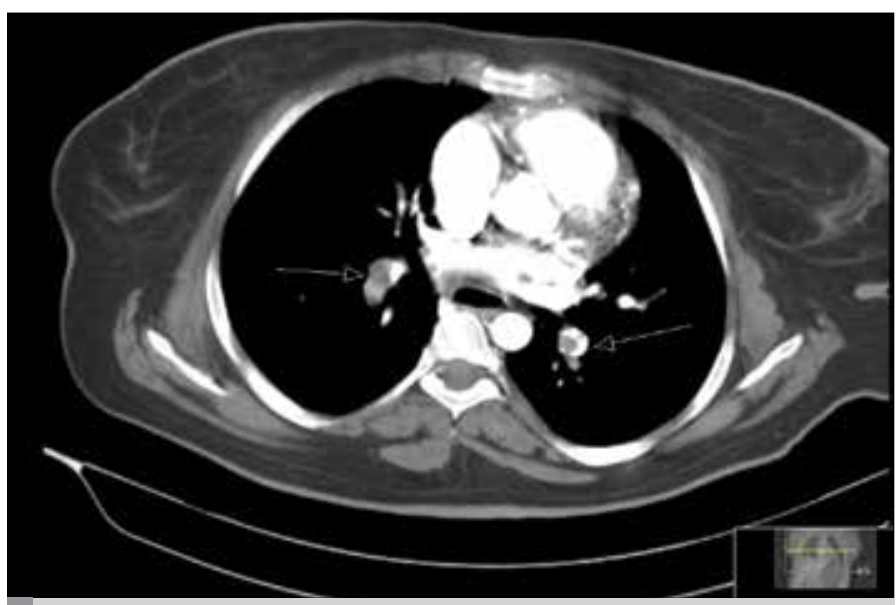

FIGURE 1. Thrombus in both pulmonary arteries

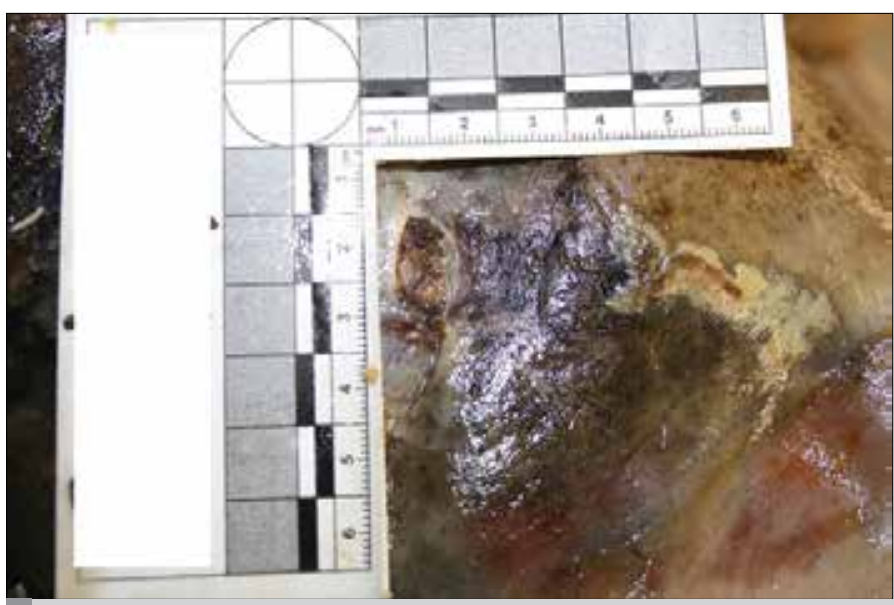

FIGURE 2. Appearance of knife wound injury during autopsy

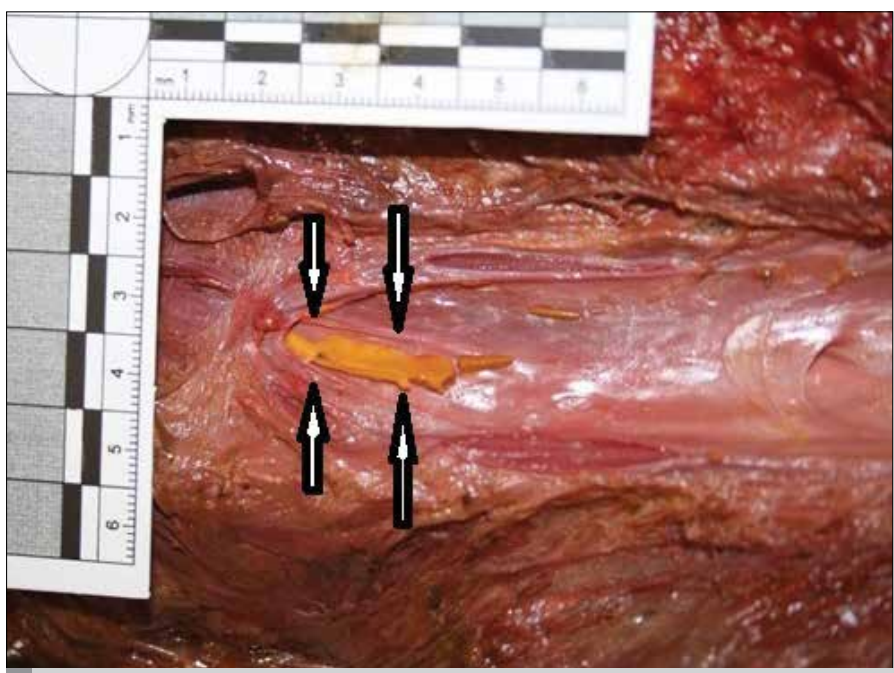

FIGURE 3. Thrombus in the femoral vein

volving skin-subcutaneous-muscle tissues that did not cause large vessel damage, with the wound edges having a regular course. Because of decay and surgical intervention, angular characteristics could not be defined (Figure 2). 
Internal examination revealed that the brain had a muddy consistency, ribs and sternum were fractured because of resuscitation procedures, heart was bagged, the pulmonary artery and lungs were decayed, and larva activity in the bronchi and decay findings in other organs were observed. In the vascular dissection, besides findings of partial decay in the abdominal aorta, pelvic, femoral, and lower leg arteries, no macroscopic pathology changes were observed. In addition, besides findings of partial decay observed in the inferior vena cava, pelvic vein, right femoral vein, deep thigh veins of both legs, and muscle tissues of both legs, no macroscopic pathological change was observed. A yellow, broad thrombus measuring $3 \times 0.2 \mathrm{~cm}$ was found in the left femoral vein lumen near the injury site (Figure 3).

Microscopic examination revealed severe autolysis, which prevented the identification of organs and diagnosis. Gas chromatographymass spectrometry revealed no toxic substance.

In the combined evaluation of clinical data and autopsy findings, the conclusion of pulmonary embolism was obtained, which had developed in association with the stab wound injury.

Informed consent was obtained from the Forensic Medicine Council who participated in this case.

\section{Discussion}

Pulmonary embolism is the third most common cause of death, which occurs within $24 \mathrm{~h}$ in cases of major trauma before an anticoagulant prophylaxis has been administered $(7,8)$. According to classic references, pulmonary embolism is most frequently observed within 5-7 days of trauma, although it may be occasionally observed before 4 days (9). Recent studies have described cases of pulmonary emboli that formed in the early stage of trauma, i.e., within $1-4$ days $(7,9)$. In a study regarding penetrating injuries to the iliac vein, only four of 48 patients who survived surgery developed pulmonary emboli and deep vein thrombus after $24 \mathrm{~h}$, causing death in one case (10). Studies have reported that the earliest period for trauma-related pulmonary embolism developing was 1 day, and in our case, considering the time between presentations, the period was determined to be $16 \mathrm{~h}$.

Pulmonary embolism developing 3-7 days after the onset of deep vein thrombosis leads to death within $1 \mathrm{~h}$ of the onset of symptoms in $10 \%$ of cases. Clinical diagnosis cannot be made in most cases that die during this period. In 5\%-10\% of cases, pulmonary embolism is manifested by shock and findings of hypotension. Laboratory findings of impaired right ventricle function without shock have been reported in 50\% of cases. The majority of deaths (>90\%) occur in untreated patients because pulmonary embolism could not be diagnosed. It has been reported that $<10 \%$ of all deaths occur in treated patients $(2,9)$.

The D-Dimer level, compression ultrasonography, ventilation-perfusion scintigraphy, $C T$, pulmonary angiography, and echocardiography are helpful for diagnosing pulmonary embolism $(2,8)$. Therefore, in patients with findings of shock and hypotension, examination and treatment must be made with respect to pulmonary embolism. In the current case, the patient presented to the hospital after shock developed and after a period of $12 \mathrm{~h}$ elapsed from the onset of symptoms to death.

Examinations revealed an hematoma area in the muscles on Doppler ultrasound, and the deep and superficial femoral artery branches at the level of the lesion were observed to have been pushed and remained under pressure. Vascular pathology was not considered for the vascular structures. The hematoma located in the left thigh owing to the pressure on the vascular structures was considered to have initiated pulmonary embolism formation because of disrupted circulation as a result of the effect of pressure. When the patient applied for the shock after 16 hours, on echocardiography right ventricular dilatation findings, in thorax CT and dynamic thoracic CT in both inferior pulmonary artery branches hypodense thrombus were detected.

The finding of right ventricle dilatation was interpreted as impaired right ventricle function. As time had elapsed because the trauma was short, pulmonary embolism formation is noteworthy. To the best of our knowledge, there is no case in the literature similar to the case presented here.

It was considered that early stage pulmonary embolism developed after stab wound resulting in impaired circulation by compressing the intramuscular hematoma without any vascular damage.

\section{Conclusion}

Cases with a pressure effect in stab wound injuries without vascular injury are at risk for pulmonary embolism and should be clinically monitored. The physician has a legal responsibility to inform the forensic authorities about these types of injuries, which can result in death. The findings obtained from an autopsy performed on a forensic case are extremely important in the clarification of the event. As the current case had not been notified as a forensic case, exhumation was performed after 39 days, and an autopsy was performed for forensic investigation. However, the time period that had elapsed limited the autopsy findings. Thus, it should not be forgotten that all kinds of emergency cases could be suspicious forensic cases.

Informed Consent: Informed consent was obtained from the Forensic Medicine Council.

Peer-review: Externally peer-reviewed.

Author contributions: Concept - S.P., O.C.; Design - N.A., S.P., M.D.; Supervision - O.C.; Resource - M.O.; Materials - E.O.; Data Collection and/or Processing - O.E., M.O.; Analysis and/or Interpretation - S.P., O.E., N.A.; Literature Search M.O., E.O., S.P., N.A.; Writing - S.P., N.A., M.D., O.C.; Critical Reviews - O.C.

Acknowledgements: The authors would like to thank Emine Şamdancı and Ahmet Çelebi for their assistance in the examination and writing of this study. 
Conflict of Interest: No conflict of interest was declared by the authors.

Financial Disclosure: The authors declared that this study has received no financial support.

\section{References}

1. Tanrıverdi MH, Abakay A. Acute pulmonary embolism. J Göztepe Med 2012; 27: 30-6. [CrossRef]

2. Torbicki A, Perrier A, Konstantinides S, Agnelli G, Galiè N, Pruszczyk P, et al. Thrombolysis during cardiopulmonary resuscitation should be addressed in guidelines for pulmonary embolism. Eur Heart J 2008; 29: 2276-315. [CrossRef]

3. Ro A, Kageyama N, Tanifuji T, Fukunaga T. Pulmonary thromboembolism: overview and update from medicolegal aspects. Leg Med 2008; 10: 57-71. [CrossRef]

4. Lucena J, Rico A, Vázquez R, Marín R, Martínez C, Salguero M, et al. Pulmonary embolism and sudden-unexpected death: prospective study on 2477 forensic autopsies performed at the Institute of Legal Medicine in Seville. J Forensic Leg Med 2009; 16: 196-201. [CrossRef]

5. Ünlüer EE, Denizbaşı A. Management and treatment of pulmonary embolism. J Res Dis 2002; 13: 67-72.

6. Anderson FA, Spencer FA. Risk factors for venous thromboembolism. Circulation 2003; 107: 9-16.

7. Spencer Netto F, Tien H, Ng J, Ortega S, Scarpelini S, Rizoli SB, et al. Pulmonary emboli after blunt trauma: timing, clinical characteristics and natural history. Injury 2012; 43: 1502-6. [CrossRef]

8. Paffrath T, Wafaisade A, Lefering R, Simanski C, Bouillon B, Spanholtz T, et al. Trauma Registry of DGU. Venous thromboembolism after severe trauma: incidence, risk factors and outcome. Injury 2010; 41: 97-101. [CrossRef]

9. Menaker J, Stein DM, Scalea TM. Incidence of early pulmonary embolism after injury. J Trauma 2007; 63: 620-4. [CrossRef]

10. Kalcioglu MT, Celbis O, Mizrak B, Firat Y, Selimoglu E. Traumatic thrombosis of internal carotid artery sustained by transfer of kinetic energy. Am J Forensic Med Pathol 20012; 33: 179-80. 